\title{
Report
}

\section{Audit of Platelet Returns at the Golden Jubilee National Hospital (March 2014-March 2015)}

\author{
Diana Jodeh ${ }^{1}$, Sanjeet Avtaar Singh ${ }^{1,}$, , Vivian Bader ${ }^{1}$, Peter Lang ${ }^{1}$, Elaine Harrison ${ }^{2}$, \\ Cathy Collins ${ }^{2}$, Alan Kirk ${ }^{1}$ \\ ${ }^{1}$ Department of Cardiothoracic Surgery, Golden Jubilee National Hospital, Clydebank, UK \\ ${ }^{2}$ Blood and Transfusion, Golden Jubilee National Hospital, Clydebank, UK
}

Email address:

Sanjeet_86@hotmail.com (S. A. Singh)

${ }^{*}$ Corresponding author

To cite this article:

Diana Jodeh, Sanjeet Avtaar Singh, Vivian Bader, Peter Lang, Elaine Harrison, Cathy Collins, Alan Kirk. Audit of Platelet Returns at the Golden Jubilee National Hospital (March 2014-March 2015). International Journal of Cardiovascular and Thoracic Surgery.

Vol. 3, No. 4, 2017, pp. 23-27. doi: 10.11648/j.ijcts.20170304.11

Received: June 8, 2017; Accepted: June 30, 2017; Published: August 16, 2017

\begin{abstract}
Platelet usage during mechanical circulatory support is well described in the literature. However, there is a limited shelf life on platelets. Platelets were required on site when a patient is placed on mechanical circulatory support. We audited the amount of platelet returns in a tertiary referral center for mechanical circulatory support. The standard for platelet wastage was $<12 \%$ of platelets used as determined by the excellence criteria by NHS Scotland.
\end{abstract}

Keywords: Mechanical Circulatory Support, Extracorporeal Membranous Oxygenation (ECMO), Platelet Returns

\section{Background}

Platelet demands have steadily increased according to NHS SCOTLAND BETTER BLOOD TRANSFUSION's latest audit report (2012). Platelet demand in the current year is expected to rise by $5 \%$, following a rise of $8.6 \%$ last year. There are several reasons to explain this continuing expectant rise of platelet demands. In NHSBT's latest annual report (2012) the rising trend was also noted across Europe.

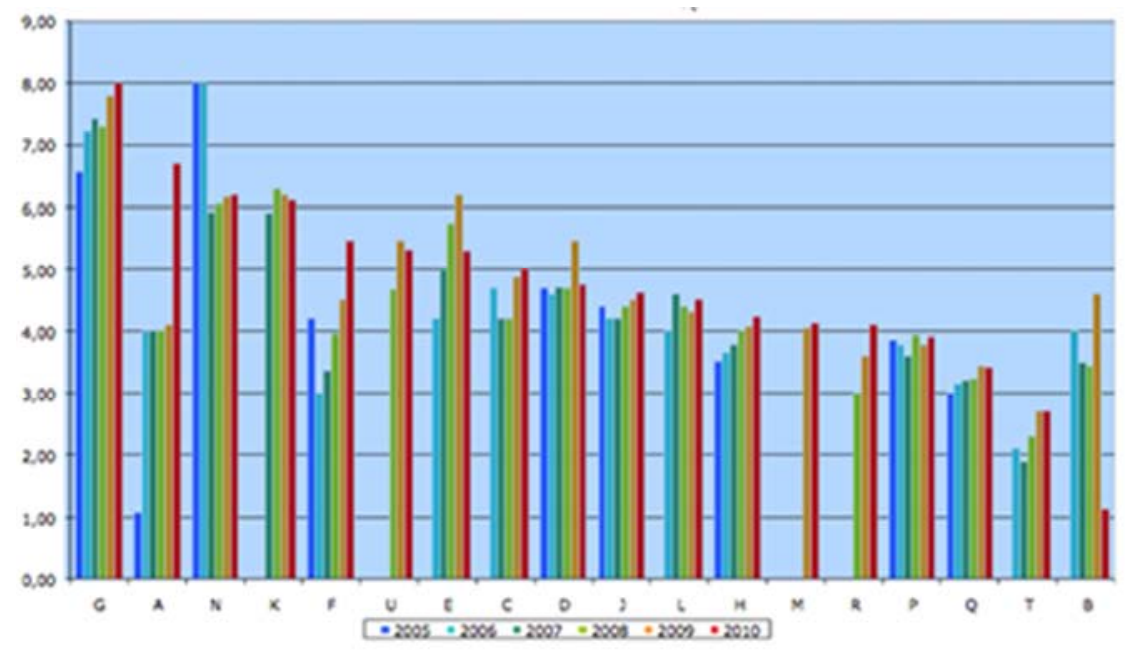

Figure 1. Annual number of platelet units issued per 1000 patients. 
This increasing demand is partially attributed to several factors nationally including improved survival from haematological conditions and malignancies, trauma and other sources of massive haemorrhage alongside liver disease and gastrointestinal bleeding. Liver disease associated with bleeding has become more common in the UK and antiplatelet drugs can increase the risk of the development of gastric ulcers that can bleed [1]. In our unit, the regional heart and lung center, we note the increase in anti-platelet drug usage in the last ten years and clinicians are utilizing more than one anti-platelet agent. However the increment in platelet returns does not reflect solely increasing transfusion demands. We therefore decided to look into each platelet return in further detail.

This audit was convened by Mr Alan Kirk (Consultant Thoracic Surgeon and Director of Medical Education), alongside Mrs Elaine Harrison and Mrs Cathy Collins (Transfusion Practitioner). The audit was proposed to address the sudden increment in platelet returns this fiscal year in comparison to last. According to the Key Performance Index standards set out by NHS Scotland, platelet returns of $<12 \%$ constituted excellence which has been achieved by this unit since its inception. However over the last year, it was noted that there was a sudden increment in our platelet returns thus prompting this detailed audit.

The audit was carried out by Mr Sanjeet Singh Avtaar Singh and Miss Diana Jodeh a medical student currently on electives. The manuscript was reviewed by Mr Peter Lang and Miss Vivian Bader.

\section{Aims \& Objectives}

The primary aim of this project is to ascertain if the increase in platelet returns from the Golden Jubilee National Hospital is confounded by other aetiologies and changes in service provision and local guidelines. It also aims to investigate the reasons behind an increased returns rate that has been highlighted by a drop in Key Performance Index measures noted by NHS Scotland and NHS SCOTLAND BETTER BLOOD TRANSFUSION.

Objectives and Outcomes

To implement measures of change in current practice and highlight potential shortcomings that has potentially let to the increased returns rate.

This includes provision of longer shelf life platelets, introduction of targeted therapy augmented by point of care tests (TEG or ROTEM) alongside potential involvement of haematologists.

\section{Standards}

The standard for platelet wastage was $<12 \%$ of platelets used as determined by the excellence criteria by NHS Scotland.

\section{Methodology}

All platelet wastages were recorded from 1/4/2014 to $31 / 3 / 2015$. This included platelets that were allocated but not used, platelets that were past their shelf life and wrongly stored platelets. Any adverse events were also noted. Platelet wastages were retrospectively analysed for reasons for allocation, shelf life, 'milk-run' or out of hours delivery of platelets, reasons for wastage, request location, and concomitant transfusions of other blood products. For platelets that were allocated to patients, their platelet count were also noted.

Data collection was done by matching the platelet returns that were coded via unit numbers to $\mathrm{CHI}$ numbers of patients (if allocated). These were then cross-checked with electronic patient records for clinical information. The most detailed reason for discard is available for Platelets with discard codes introduced in Traceline from 9th September 2012.

Data was analysed using descriptive statistics. Data was collected by DJ under supervision of SS. Data analysis was done by SS. There were no sources of external funding.

\section{Result}

Table 1. Platelet usage at the Golden Jubilee National Hospital.

\begin{tabular}{|c|c|c|c|c|c|c|c|}
\hline \multirow{2}{*}{\multicolumn{2}{|c|}{ Golden Jubilee Blood Bank }} & \multicolumn{6}{|c|}{ Year 2014/2015 } \\
\hline & & \multirow{2}{*}{$\begin{array}{l}\text { Apr } 2014 \\
69\end{array}$} & \multirow{2}{*}{$\begin{array}{l}\text { May } 2014 \\
51\end{array}$} & \multirow{2}{*}{$\begin{array}{l}\text { Jun } 2014 \\
51\end{array}$} & \multirow{2}{*}{$\begin{array}{l}\text { July } 2014 \\
107\end{array}$} & \multirow{2}{*}{$\begin{array}{l}\text { Aug } 2014 \\
75\end{array}$} & \multirow{2}{*}{$\begin{array}{l}\text { Sept } 2014 \\
50\end{array}$} \\
\hline \multirow{4}{*}{ Characteristics (n) } & Total units booked in & & & & & & \\
\hline & CMV negative (\%) & 39.1 & 29.4 & 51.0 & 29.0 & 44.0 & 46.0 \\
\hline & 2 days or less to expiry $(\%)$ & 81.2 & 84.3 & 86.3 & 79.4 & 62.7 & 72.0 \\
\hline & Median Days to expiry & 1 & 1 & 2 & 1 & 2 & 2 \\
\hline \multirow{4}{*}{ Stock movements (n) } & Total units to patients & 66 & 50 & 47 & 104 & 77 & 43 \\
\hline & $\begin{array}{l}\text { Returns to stock as a percentage of issue } \\
\text { events }\end{array}$ & 16.4 & 11.1 & 10.0 & 19.7 & 16.3 & 0 \\
\hline & Units fated in other blood bank & 0 & 0 & 0 & 0 & 0 & 0 \\
\hline & Total units fated & 68 & 54 & 49 & 107 & 77 & 49 \\
\hline \multirow{3}{*}{ Fate Breakdown } & Transfused (\%) & 89.7 & 90.7 & 91.8 & 91.6 & 92.2 & 85.7 \\
\hline & Time Expired (\%) & 8.8 & 7.4 & 8.2 & 8.4 & 6.5 & 12.2 \\
\hline & Discarded & 1.5 & 1.9 & - & - & 1.3 & 2.0 \\
\hline
\end{tabular}


Table 1. Continued.

\begin{tabular}{|c|c|c|c|c|c|c|c|c|}
\hline \multicolumn{2}{|c|}{ Golden Jubilee Blood Bank } & \multirow{2}{*}{$\begin{array}{l}\text { Oct } 2014 \\
49\end{array}$} & \multirow{2}{*}{$\begin{array}{l}\text { Nov } 2014 \\
63\end{array}$} & \multirow{2}{*}{$\begin{array}{l}\text { Dec } 2014 \\
82\end{array}$} & \multirow{2}{*}{$\begin{array}{l}\text { Jan } 2015 \\
27\end{array}$} & \multirow{2}{*}{$\begin{array}{l}\text { Feb } 2015 \\
81\end{array}$} & \multirow{2}{*}{$\begin{array}{l}\text { Mar } 2015 \\
64\end{array}$} & \multirow{2}{*}{$\begin{array}{l}\begin{array}{l}\text { Over } 12 \\
\text { months }\end{array} \\
769\end{array}$} \\
\hline \multirow{5}{*}{ Characteristics (n) } & Total units booked in & & & & & & & \\
\hline & CMV negative (\%) & 51.0 & 28.6 & 29.3 & 44.4 & 38.3 & 53.1 & 38.9 \\
\hline & 2 days or less to expiry (\%) & 73.5 & 85.7 & 80.5 & 77.8 & 79.0 & 71.9 & 77.8 \\
\hline & Median Days to expiry & 2 & 1 & 2 & 1 & 2 & 2 & 2 \\
\hline & Total units to patients & 45 & 56 & 73 & 20 & 72 & 60 & 710 \\
\hline \multirow[b]{2}{*}{ Stock movements(n) } & Average issue events per unit & 1.27 & 1.13 & 1.16 & 1.05 & 1.17 & 1.25 & 1.14 \\
\hline & $\begin{array}{l}\text { Returns to stock as a percentage of } \\
\text { issue events }\end{array}$ & 35.1 & 15.9 & 20.0 & 19.0 & 18.2 & 34.7 & 18.9 \\
\hline \multirow{5}{*}{ Fate Breakdown } & Units fated in other blood bank & 0 & 0 & 0 & 0 & 0 & 0 & 0 \\
\hline & Total units fated & 48 & 64 & 82 & 27 & 74 & 72 & 771 \\
\hline & Transfused (\%) & 77.1 & 82.8 & 80.2 & 63.9 & 81.1 & 73.6 & 84.5 \\
\hline & Time Expired (\%) & 22.9 & 17.2 & 18.5 & 37.0 & 18.9 & 26.4 & 14.8 \\
\hline & Discarded & - & - & 1.2 & - & - & - & 0.6 \\
\hline
\end{tabular}

As noted above, $14.8 \%$ of the platelets were time expired with $0.6 \%$ discarded due to improper storage and transport at the wrong temperature. Of the $14.8 \%(n=114)$ of the platelets that were expired, the median time to expiry was 40 hours.

\subsection{Not Allocated}

$50.9 \%(n=58)$ of these platelets remained unallocated at the time of expiry. These platelets were neither allocated to any patients nor used for any procedures.

\subsection{Thoracic}

$1.8 \%(n=2)$ of platelets were allocated but not used for post-operative complications of thoracic surgery (1 thoracotomy and 1 oesophagectomy). Both cases required concomitant Packed Red Cells (PRC) and Fresh Frozen Plasma (FFP) transfusions as well. All 3 units were brought in out of hours as an emergency.

\subsection{Cardiac}

$14.9 \%(n=17)$ of platelets were allocated for cardiac surgery complications but not used. Of these 11 units were on site and 8 units were brought in out of hours. The breakdown of these include (5 CABG alone, 5 CABG + AVR, 2 AVRs, 1 AVR +MVR, 1 Aortic Root Replacement, 1 Aortic Dissection Repair, 1 for MVR with LV rupture, 1 pericardiocentesis). 12 of these cases had concomitant transfusion of FFPs, PRCs, and cryoprecipitate.

\subsection{National Services}

As our centre also serves as the advanced heart failure unit as well as the Cardiac Transplant Service for Scotland, we also provide Extracorporeal membranous oxygenation services (ECMO) and Ventricular Assist Devices (VADS). Our hospital protocol dictates that if there is a patient receiving ECMO, 2 units of platelets should be available at all times on site. This corresponds to $24.6 \%(\mathrm{n}=28)$ of platelet returns with another $3.5 \%(n=4)$ allocated but unused by patients undergoing VAD.

\subsection{ECMO}

For the patients undergoing ECMO, 3 patients were post-transplant with Primary Graft Dysfunction. These patients did not require any other blood products. 10 units were stored on site with 18 units that were transported out of hours. 18 patients required concomitant blood transfusions.

\section{6. $V A D$}

For the patients whom required a VAD, 2 patients required concomitant transfusions. 3 units were transferred out of hours and 1 unit was stored on site.

\subsection{Cardiac Transplant}

$4.4 \%(n=5)$ of units were allocated but unused by patients who underwent a cardiac transplant. Of these 2 units were on site with 3 transferred in out of hours. All of these patients required concomitant transfusion of blood products.

The breakdown of platelet groups is on the following page.

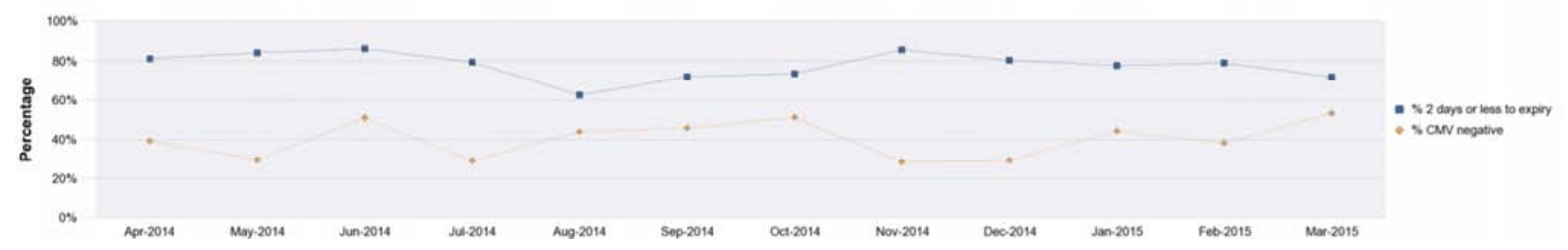




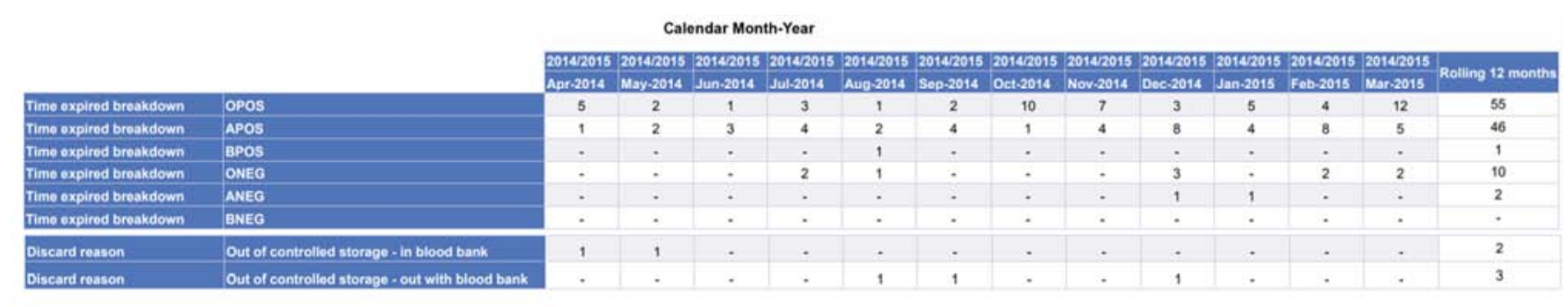

(- indicates no units were used)

Figure 2. Adult platelets stock activity at the Golden Jubilee National Hospital.

\subsection{Comments}

Excluding the ECMO patients (as they require 2 units of platelets on standby at all times as per agreed national standards (implemented in all ECMO centres across the UK) the platelet returns is $11.2 \% \quad(n=86)$ which is $<12 \%$ as stipulated by NHS Scotland. This figure could be lower as transfusion services at the GJNH sometimes use products allocated to ECMO patients prior for other patients in emergencies while awaiting stock for the ECMO patients arriving. Given the special circumstances, ECMO platelet allocations should be excluded from the final returns count.

\section{Conclusions}

Excluding the platelet returns allocated for ECMO patients, GJNH platelet returns rate are within the excellence criteria $(11.2 \%)$.

ECMO centres will essentially require platelets on standby thereby increasing platelet wastage. There should be a separate criterion for these centres with regards to platelet returns.

\section{Discussion}

Platelet use in ECMO is well described in the literature. Haemorrhagic complications occurs in up to $35 \%$ of infants during ECMO and has devastating outcomes in this cohort [2]. Platelet number and function have a significant impact on primary haemostasis. In a recent single-center retrospective cohort study of 100 adults who received ECMO for acute respiratory failure by Abrams et al [3], the relationship between days on ECMO and daily percentage of platelets compared to the first post-cannulation platelet count.

Using a multivariable logistic regression model with backwards stepwise elimination to identify clinical predictors of severe thrombocytopenia $(\leq 50,000 / \mu \mathrm{L})$ while on ECMO, they noted that days on ECMO was not associated with a decrease in platelet count in the unadjusted analysis $(\beta-0.85,95 \% \mathrm{CI}-2.05$ to 0.36$)$, nor after considering and controlling for days hospitalized prior to ECMO, APACHE II score, platelet transfusions, and potential thrombocytopenia-inducing medications $(\beta-0.83,95 \% \mathrm{CI}$ -1.9 to 0.25$)$.

There is some activation prolonged activation of endothelial and coagulation systems, including intercellular adhesion molecule, E-selectin, and tissue factor [4, 5]. In VAD designs, hemocompatibility is often given priority. Stasis, haemolysis, turbulent flow or retrograde flow are some issues that may occur with VADs. The interaction with blood on VAD surfaces may also precipitate some of its major complications such as thrombosis, bleeding and infection [6]. Two well understood mechanisms here are acquired von Willebrand disease and platelet aggregation. Large amounts of von Willebrand factor (vWF) multimers are loss due to the high sheer stress. This alters the $3 \mathrm{D}$ structure and enhances proteolysis of vWF [7]. A high rate of von Wlilebrand disease was noted in patients with bleeding angiodysplasia mimicking the pathophysiology of high sheer stress as it would in a VAD [6]. Other findings of note include impaired collagen binding capacity and ristocetin cofactor activity, a measure of vWF factor binding to platelets, were lower in all VAD patients. [8-10]. Patients with blood type $\mathrm{O}$ have been noted to have lower baseline levels of vWF compared with other blood groups, and 1 study found evidence of frequent bleeding in patients with blood group O. [8]

In another single centre retrospective study on the amount of blood products received by adults during ECMO, they noted that average daily platelet transfusion increased with recent antiplatelet agents $(\mathrm{P}=0.015)$ and maximum $\mathrm{Hb}$ decline of $>5.5 \mathrm{~g} / \mathrm{d}$ l during ECMO $(\mathrm{P}=0.011)$. Average daily platelet transfusion $>3$ units was also associated with increased ECMO duration $(\mathrm{P}=0.024)$ [11].

\section{References}

[1] Estcourt LJ, Birchall J, Allard S, Bassey SJ, Hersey P, Kerr JP, et al. Guidelines for the use of platelet transfusions. British Journal of Haematology. 2017; 176(3):365-94.

[2] Stallion A, Cofer BR, Rafferty JA, Ziegler MM, Ryckman FC. The significant relationship between platelet count and haemorrhagic complications on ECMO. Perfusion. 1994; 9(4):265-9.

[3] Abrams D, Baldwin MR, Champion M, Agerstrand C, Eisenberger A, Bacchetta $\mathrm{M}$, et al. Thrombocytopenia and extracorporeal membrane oxygenation in adults with acute respiratory failure: a cohort study. Intensive Care Med. 2016; 42(5):844-52.

[4] John R, Panch S, Hrabe J, Wei P, Solovey A, Joyce L, et al. Activation of endothelial and coagulation systems in left ventricular assist device recipients. The Annals of thoracic surgery. 2009; 88(4):1171-9. 
[5] Gorlinger K, Bergmann L, Dirkmann D. Coagulation management in patients undergoing mechanical circulatory support. Best Pract Res Clin Anaesthesiol. 2012; 26(2):179-98.

[6] Himmelreich G, Ullmann H, Riess H, Rosch R, Loebe M, Schiessler A, et al. Pathophysiologic role of contact activation in bleeding followed by thromboembolic complications after implantation of a ventricular assist device. ASAIO J. 1995; 41(3): M790-4.

[7] Siedlecki CA, Lestini BJ, Kottke-Marchant KK, Eppell SJ, Wilson DL, Marchant RE. Shear-dependent changes in the three-dimensional structure of human von Willebrand factor. Blood. 1996; 88(8):2939-50.

[8] Crow S, Chen D, Milano C, Thomas W, Joyce L, Piacentino V, 3rd, et al. Acquired von Willebrand syndrome in continuous-flow ventricular assist device recipients. The Annals of thoracic surgery. 2010; 90(4):1263-9; discussion 9.
[9] Klovaite J, Gustafsson F, Mortensen SA, Sander K, Nielsen LB Severely impaired von Willebrand factor-dependent platelet aggregation in patients with a continuous-flow left ventricular assist device (HeartMate II). J Am Coll Cardiol. 2009; 53(23):2162-7.

[10] Uriel N, Pak SW, Jorde UP, Jude B, Susen S, Vincentelli A, et al. Acquired von Willebrand syndrome after continuous-flow mechanical device support contributes to a high prevalence of bleeding during long-term support and at the time of transplantation. J Am Coll Cardiol. 2010; 56(15):1207-13.

[11] Ang AL, Teo D, Lim CH, Leou KK, Tien SL, Koh MB. Blood transfusion requirements and independent predictors of increased transfusion requirements among adult patients on extracorporeal membrane oxygenation -- a single centre experience. Vox sanguinis. 2009; 96(1):34-43. 